\title{
Severe fever with thrombocytopenia syndrome: a systematic review and meta- analysis of epidemiology, clinical signs, routine laboratory diagnosis, risk factors, and outcomes
}

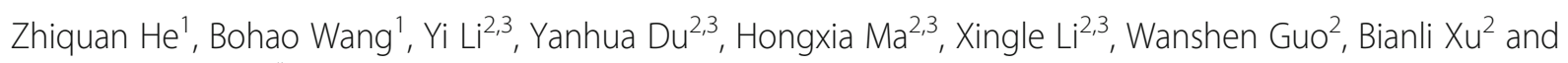
Xueyong Huang ${ }^{2,3^{*}}$

\begin{abstract}
Background: Severe fever with thrombocytopenia syndrome (SFTS) is an emerging infectious disease with the high case-fatality rate, and lack of vaccines. We aimed to systematically analysed the epidemiological characteristics, clinical signs, routine laboratory diagnosis, risk factors, and outcomes.

Methods: Documents on SFTS were collected by searching the Chinese National Knowledge Infrastructure, Wan Fang Data, PubMed, Embase, and Web of Science databases from 2011 to 2018. Meta-analysis was performed by using Review Manager and Stata software.
\end{abstract}

Results: Twenty-five articles involving 4143 cases were included. Diarrhea (odds ratio (OR) $=1.60,95 \%$ confidence interval (Cl): 1.06 to $2.42, P=0.02)$, and vomiting ( $\mathrm{OR}=1.56,95 \% \mathrm{Cl}: 1.01$ to $2.39, P=0.04)$ on admission were associated with the fatal outcomes of SFTS. Compared to patients with mild symptoms, patients with severe symptoms had significantly elevated levels of lactic acid dehydrogenase (standard mean difference (SMD) $=1.27,95 \%$ Cl: 0.59 to 1.94), alanine aminotransferase (SMD $=0.55,95 \%$ Cl: 0.24 to 0.85), aspirate aminotransferase (SMD = 1.01, 95\% Cl: 0.69 to 1.32), and creatine kinase (SMD $=1.04,95 \% \mathrm{Cl}: 0.74$ to 1.33 ) but had reduced platelet counts (SMD $=-0.87,95 \% \mathrm{Cl}:-1.16$ to $-0.58)$ and albumin levels $(\mathrm{SMD}=-1.00,95 \% \mathrm{Cl}:-1.32$ to -0.68$)$. The risk factors for poor prognosis included age (mean difference $(\mathrm{MD})=6.88,95 \% \mathrm{Cl}: 5.41$ to 8.35 ) and farming $(\mathrm{OR}=2.01,95 \% \mathrm{Cl}: 1.06$ to 3.80$)$. For the risk factors of contracting SFTS, the incidence of SFTS related to tick bites was 24\% [95\% Cl: 0.18 to 0.31 ]. The pooled case-fatality rate of SFTS patients was 18\% [95\% Cl: 0.16 to 0.21$]$.

(Continued on next page)

\footnotetext{
* Correspondence: hxyzzu@163.com

${ }^{2}$ Henan Province Center for Disease Control and Prevention, Zhengzhou,

China

${ }^{3}$ Henan Key Laboratory of Pathogenic Microorganisms, Zhengzhou, China

Full list of author information is available at the end of the article
}

C C The Author(s). 2020 Open Access This article is licensed under a Creative Commons Attribution 4.0 International License, which permits use, sharing, adaptation, distribution and reproduction in any medium or format, as long as you give appropriate credit to the original author(s) and the source, provide a link to the Creative Commons licence, and indicate if changes were made. The images or other third party material in this article are included in the article's Creative Commons licence, unless indicated otherwise in a credit line to the material. If material is not included in the article's Creative Commons licence and your intended use is not permitted by statutory regulation or exceeds the permitted use, you will need to obtain permission directly from the copyright holder. To view a copy of this licence, visit http://creativecommons.org/licenses/by/4.0/. The Creative Commons Public Domain Dedication waiver (http://creativecommons.org/publicdomain/zero/1.0/) applies to the data made available in this article, unless otherwise stated in a credit line to the data. 


\begin{abstract}
(Continued from previous page)
Conclusions: China is the country with the highest incidence of SFTS. May to July was the peak of the epidemic, and farmers were a high-risk group. The risk factor for SFTS included age (poor prognosis) and tick bites (contracting SFTS). Patients with severe diarrhea and vomiting symptoms on admission should be noted. Clinicians could use routine laboratory parameters and clinical symptoms as references for clinically suspected cases, classification of SFTS, and timely treatment, especially in basic hospitals.
\end{abstract}

Keywords: SFTS, Clinical signs, Routine laboratory diagnosis, Risk factors, Epidemiology, Outcomes, Meta-analysis

\section{Background}

Severe fever with thrombocytopenia syndrome (SFTS) is a novel emerging infectious disease that was first discovered in rural areas of eastern and central China. In 2009, a novel bunyavirus was isolated from acute-phase patient serum samples and named as severe fever with thrombocytopenia syndrome virus (SFTSV), huaiyangshan virus (HYSV), or new bunyavirus (NBV) [1-4]. It is now known as SFTSV. The disease has been reported in 23 Chinese provinces, more than 5000 cases were reported during 2009-2016, and Henan province had the highest case count, accounting for $45 \%$ of reported cases during 2011-2014 in China [2, 5, 6]. SFTS patients have been found in Japan and Korea [7, 8]. SFTSV is transmitted by tick bites, and human-to-human transmission has also been reported [9-12]. A high casefatality rate, ranging from 5 to $20 \%$, has been reported for SFTSV-infected patients in the endemic areas [13-15].

SFTS has been a serious public health concern; however, effective therapies or vaccines are not yet available, so understanding its features has important significance for the prevention and treatment of disease. In this article, we systemically searched and analysed the epidemiology, clinical signs, routine laboratory diagnosis, risk factors, and outcomes of SFTS.

\section{Methods}

\section{Literature searching}

We carefully performed a systematic search of the Chinese National Knowledge Infrastructure databases (CNKI), Wan Fang Data, PubMed, Embase, and Web of Science databases for all eligible papers (published from 2011 to 2018; English and Chinese publications) using the following search terms: "severe fever with thrombocytopenia syndrome" OR "SFTS" OR "SFTSV" OR "NBV". We also manually included additional studies obtained from the references of the original articles and searches.

\section{Inclusion and exclusion criteria}

An initial screening of the titles and abstracts was performed by two authors independently. Thereafter, two independent authors screened the full texts of the selected articles. The inclusion criteria were as follows: the article had been accepted for publication; the study provided information on SFTS patients, or the SFTS patient mentioned in the selected studies was confirmed as meeting one or more of the following criteria: (1) the virus was isolated from the patient's samples; (2) SFTSV RNA was detected in the patient's serum; (3) a 4-fold or greater increase in antibody titers was detected between a paired patient serum samples collected from the acute and convalescent phases of infection.

The exclusion criteria included abstract-only articles, case reports $(n<5)$, letters, editorials, systematic reviews, duplicated publications, overlapping data sets (articles of the same region and year or articles containing another article were collected and carefully selected by two authors), in vitro studies, studies on animals, genotype analyses or treatments, and articles in which no data were extracted.

\section{Data extraction and quality assessment}

Data were independently extracted by two reviewers from the included articles. Disagreement was resolved through discussion or consensus. Subsequently, the following information was extracted from every eligible article: the first author; year of publication; region; year of admitted patients; the timing of the symptoms; number of patients; patient's age; clinical information about SFTS patients, including symptoms (fever, myalgia, sputum, anorexia, abdominal pain, diarrhea vomiting, fatigue, gingival bleeding, headache, cough, nausea, petechiae and lymphadenopathy), routine laboratory parameters (lactic acid dehydrogenase (LDH), alanine aminotransferase (ALT), aspirate aminotransferase (AST), platelet count, albumin, creatine kinase (CK), creatinine, and white blood cell (WBC) count); interval between onset and admission; risk factors; outcomes; and the number of deaths. In addition, if there was no reliable data, we input "NA", which means "not available", during the extraction phases.

We evaluated the quality of primary studies using Study Quality Assessment Tools provided by the National Institute of Health [16]. The criteria were divided into three grades: good, fair and poor. Based on the quality assessment for studies, we identified the articles' quality ratings.

\section{Statistical analysis}

Means and standard deviation (SDs) were chosen to describe continuous variables with normal distributions. 
The medians and interquartile (IQ) ranges are shown for the interval between onset and admission, laboratory parameters and age. If the data showed medians and ranges or IQ ranges rather than the means and SDs, then the means and SDs were calculated as described by Hozo et al., Wan et al., and Luo et al. [17-19]. Each study presenting the number of patients was included for calculation of the event rates and proportions with 95\% confidence intervals (CIs) for clinical signs and outcomes. I-squared and Chi-square were chosen to reflect the heterogeneity among these studies [20]. Heterogeneity was considered significant when $P<0.05$ and $\mathrm{I}^{2}>$ $50 \%$; then, a random effect model was applied. Otherwise, a fixed effect model was used. Furthermore, publication bias was assessed by visually using Begg's funnel plot or Egger's test [21]. All of the statistical analyses were performed using Review Manager (RevMan version 5.3; Nordic Cochrane Centre, Copenhagen, Denmark) software and STATA software version 12.0 (STATA Corporation, College Station, Texas, USA).

\section{Results}

\section{Systematic review}

The study selection process and the results are shown in Fig. 1. A total of 4052 articles were retrieved after the preliminary screening from the electronic databases; 1895 articles were duplicated and removed, and 2010 of the 2157 articles were excluded after review of the titles and abstracts due to irrelevant topics (the sinonasal solitary fibrous tumours). After reading the full texts of the remaining 147 articles, 122 articles were excluded due to lack of some indicators. Finally, 25 studies were included for further meta-analysis. The detailed data are shown in Table 1. In this review, the largest numbers of reported cases and articles were from China (21 articles, 3876 cases), followed by Korea (3 articles, 218 cases) and Japan ( 1 article, 49 cases). In a period of 8 years, from 2011 to 2018, 21 articles in China were collected, which included Henan province ( 2 articles), Jiangsu province (4 article), Liaoning province (2 article), Shandong province (3 article), Hubei province (5 articles), Zhejiang province ( 2 article), Anhui province ( 2 article), and undetermined province ( 1 article). The remaining 4 articles were Korea ( 3 articles) and Japan ( 1 article). For the season, 10 of 25 articles suggested that the epidemic peak was in May to July. In terms of geographical and time trends, the two points were considered important sources of potential bias when explaining the evidence for SFTS.

\section{Clinical symptoms of SFTS}

The clinical symptoms were more representative in the comparison of fatal and non-fatal SFTS patients: 12 articles, including 887 cases, presented the clinical characteristics and were analysed and compared. Based on the timing of the symptoms, the studies were divided into two groups focusing either on admission (9 studies) or during the hospitalization (3 studies). Since the definition of fever was different in various studies, so we did not consider fever symptoms. Diarrhea and vomiting on admission were associated with the fatal outcomes of SFTS disease $(\mathrm{OR}=1.60,95 \% \mathrm{CI}: 1.06$ to $2.42, P=0.02$; $\mathrm{OR}=1.56,95 \%$ CI: 1.01 to $2.39, P=0.04$ ), respectively (Fig. 2 ). However, there was no significant heterogeneity in other signs either on admission or during hospitalization (Table S1).

Fourteen pooled positive rates of clinical symptoms were calculated, and 15 studies focusing on admission used the random effect model due to symptoms, with Isquared values $>50 \%$. The included studies, pooled positive rates $(95 \% \mathrm{CI}), P$ values (I-squared) and sensitive analyses are presented in Table S2.

\section{Routine laboratory diagnosis of SFTS}

Mild cases were accompanied with fever $\left(37.2^{\circ} \mathrm{C}-39^{\circ} \mathrm{C}\right)$, fatigue, gastrointestinal symptoms, leukocyte count decreased, platelet count was $(50-130) \times 10^{9} / \mathrm{L}$, and the levels of AST, ALT, CK, and LDH were less than two times the upper limit of normal (ULN) values. Severe cases had the high fever $\left(39^{\circ} \mathrm{C}-40^{\circ} \mathrm{C}\right)$, fatigue, obvious gastrointestinal symptoms, neurological symptoms, platelet count was $(30-50) \times 10^{9} / \mathrm{L}$, and sharply elevated (more than five times ULN) of LDH, ALT, AST, and CK. As shown in Fig. 3, the routine laboratory findings of patients with severe and mild symptoms were compared. Patients with severe symptoms had significantly elevated levels of LDH (SMD $=1.27,95 \% \mathrm{CI}: 0.59$ to 1.94), ALT (SMD $=0.55,95 \%$ CI: 0.24 to 0.85$)$, AST $(\mathrm{SMD}=1.01,95 \% \mathrm{CI}: 0.69$ to 1.32$)$, and $\mathrm{CK}(\mathrm{SMD}=$ 1.04, $95 \%$ CI: 0.74 to 1.33 ) compared to the patients with mild symptoms but showed reduced levels of platelets $(\mathrm{SMD}=-0.87,95 \% \mathrm{CI}:-1.16$ to -0.58$)$ and albumin $(\mathrm{SMD}=-1.00,95 \% \mathrm{CI}:-1.32$ to -0.68$)$. There were no differences in mild and severe SFTS cases regarding the WBC count $(\mathrm{SMD}=-0.28,95 \% \mathrm{CI}:-0.76$ to 0.2$)$. The one study showed that serum creatinine in 115 patients' blood ranged from 4.9 to $370 \mu \mathrm{mol} / \mathrm{L}$. The median creatinine was $74.9 \mu \mathrm{mol} / \mathrm{L}$ in 74 patients with mild symptoms, and $93 \mu \mathrm{mol} / \mathrm{L}$ in 41 patients with severe symptoms. The serum creatinine was significantly higher in patients with severe symptoms compared with the patients with mild symptoms $(P<0.05)[26]$.

\section{Risk factors for SFTS}

For the risk factors of poor prognosis, we analysed age, the interval between onset and admission, farming and tick bites. Age was the critical risk factor for SFTS patients (MD $=6.88,95 \%$ CI: 5.41 to 8.35 ), but the interval between onset and admission had no significant association with the disease $(\mathrm{MD}=-0.25,95 \% \mathrm{CI}:-0.71$ to 


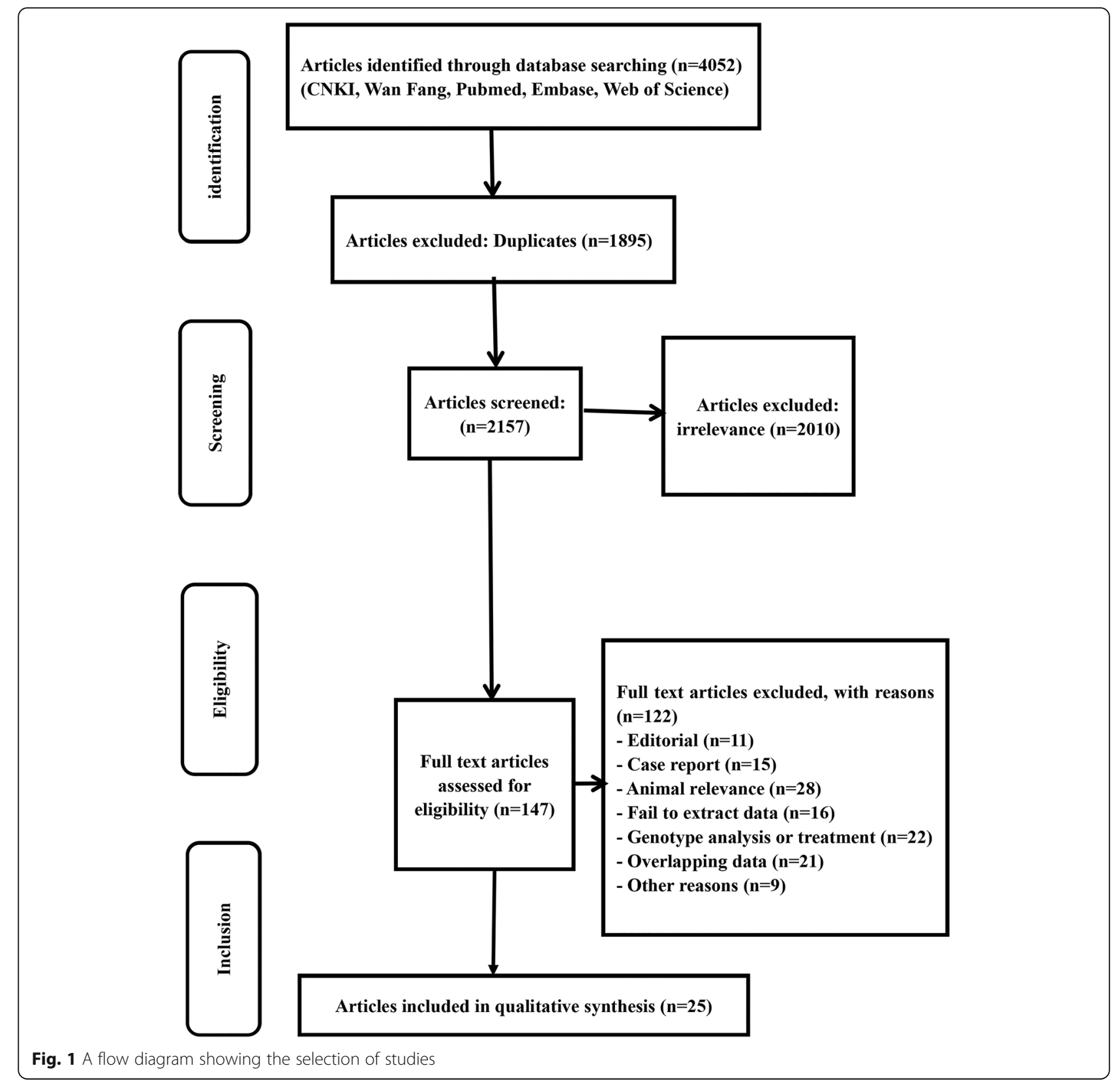

0.22). Engaging in agricultural activity was a risk factor, resulting in the occurrence of death case $(\mathrm{OR}=2.01$, 95\% CI: 1.06 to 3.80 ). One hundred thirty two fatal cases and 359 non-fatal cases were extracted to study the relationship between tick bites and fatal outcomes. The results showed that tick bites were not a risk factor for death case (OR $=0.98,95 \% \mathrm{CI}: 0.40$ to 2.42$)$, and the fatality due to severity of the disease and personal conditions. For the SFTS cases, tick bites play a key role in the risk of infection, which were considered to be the main route of transmission of SFTSV. The 11 articles were analysed and showed that $24 \%$ [95\% CI: 0.18 to
0.31] (284 biters in 1228 cases) had been bitten by ticks, indicating the incidence of SFTS related to tick bites (Fig. 4).

\section{Outcomes of SFTS patients}

The pooled case-fatality rate of SFTS patients was 18\% [95\% CI: 0.16 to 0.21 ] (735 deaths in total among 4143 cases). According to country (China, Japan, and Korea), the pooled mean mortality rates were 0.16 [ $95 \%$ CI: 0.15 to 0.18 ], 0.31 [95\% CI: 0.18 to 0.44$]$, and 0.30 [95\% CI: 0.13 to 0.46 ], respectively. In the heterogeneity analysis, the I-squared value was $58.2 \%$, suggesting that there was significant heterogeneity 
Table 1 Characteristics of included studies in Meta-analysis

\begin{tabular}{|c|c|c|c|c|c|c|c|c|}
\hline Study & $\begin{array}{l}\text { Publication } \\
\text { year }\end{array}$ & Region & $\begin{array}{l}\text { Year of admitted } \\
\text { patients }\end{array}$ & Age & $\begin{array}{l}\text { Case } \\
\text { Number }\end{array}$ & $\begin{array}{l}\text { Death } \\
\text { Number }\end{array}$ & $\begin{array}{l}\text { Quality } \\
\text { Rating }\end{array}$ & $\begin{array}{l}\text { interval between } \\
\text { onset and admission }\end{array}$ \\
\hline Bao et al. [22] & 2011 & Jiangsu, China & 2007 & $61.4 \pm 10.5^{\mathrm{a}}$ & 7 & 1 & Poor & $4(3-7.5)^{b}$ \\
\hline Deng et al. [23] & 2012 & Liaoning, China & 2011 & $55.7 \pm 14.7$ & 40 & 6 & Poor & $5.5(1-10)^{d}$ \\
\hline Gai et al. [24] & 2012 & Shandong, China & 2008-2011 & $61(40-83)^{d}$ & 59 & 11 & Fair & NA \\
\hline Zhang et al. [25] & 2012 & Hubei, China & 2010 & $54.4 \pm 9.1$ & 49 & 8 & Fair & $10(7-14)^{b}$ \\
\hline Deng et al. [26] & 2013 & Liaoning, China & 2010-2011 & $55(17-89)^{d}$ & 115 & 14 & Good & $5(1-14)^{d}$ \\
\hline Sun et al. [27] & 2013 & Hubei, China & 2012 & $55(30-78)^{d}$ & 34 & 3 & Fair & NA \\
\hline Ding et al. [28] & 2014 & NA & 2010-2011 & $61(23-82)^{d}$ & 59 & 7 & Fair & $6(1-13)^{d}$ \\
\hline Sun et al. [29] & 2014 & Zhejiang, China & 2011-2013 & $66(31-84)^{d}$ & 65 & 9 & Fair & NA \\
\hline Xu et al. [30] & 2015 & Henan, China & 2007-2011 & $51.4 \pm 13.0$ & 422 & 68 & Fair & NA \\
\hline Shin et al. [31] & 2015 & South Korea & 2013 & $69(28-84)^{d}$ & 35 & 16 & Fair & $4(1-9)^{d}$ \\
\hline Choi et al. [32] & 2016 & South Korea & 2013-2015 & $67.5(57-76)^{b}$ & 172 & 56 & Good & $4(3-6)^{b}$ \\
\hline Kato et al. [33] & 2016 & Japan & 2013-2014 & $78(65-84)^{b}$ & 49 & 15 & Good & $4(2-5)^{b}$ \\
\hline Peng et al. [34] & 2016 & Hubei, China & 2014 & $53.8(24-79)^{d}$ & 53 & 9 & Poor & NA \\
\hline Xiong et al. [35] & 2016 & Hubei, China & 2015 & $58(27-91)^{d}$ & 179 & 34 & Good & NA \\
\hline Xu et al. [36] & 2016 & Shandong, China & 2011-2015 & $62.1 \pm 10.6$ & 113 & 21 & Fair & NA \\
\hline Zhao et al. [37] & 2016 & Jiangsu, China & 2010-2014 & $57.6(38-78)^{d}$ & 40 & 7 & Fair & NA \\
\hline Zhang et al. [38] & 2016 & Hubei, China & 2015 & $60(28-91)^{d}$ & 115 & 21 & Poor & NA \\
\hline Hu et al. [39] & 2017 & Jiangsu, China & 2011-2013 & $56.5(76-83)^{d}$ & 89 & 19 & Fair & $8.5(1-50)^{b}$ \\
\hline Hu et al. [40] & 2018 & Zhejiang, China & 2014-2017 & $57.8 \pm 12.662$ & 25 & 5 & Fair & $6(0-11)^{b}$ \\
\hline Jia et al. [41] & 2018 & Jiangsu, China & 2010-2016 & $59(51-67)^{b}$ & 90 & 20 & Fair & $8(7-9)^{b}$ \\
\hline Song et al. [42] & 2018 & Anhui, China & 2011-2017 & $64(24-86)^{d}$ & 87 & 12 & Poor & NA \\
\hline Xia et al. [43] & 2018 & Anhui, China & 2014-2017 & $62 \pm 10.82$ & 86 & 12 & Fair & NA \\
\hline Li et al. [44] & 2018 & Henan, China & 2011-2017 & $61.4 \pm 12.2$ & 2096 & 340 & Good & $5(4-7)^{b}$ \\
\hline Kwon et al. [45] & 2018 & Korea & 2015-2016 & $60 \pm 7$ & 11 & 1 & Fair & NA \\
\hline Xu et al. [46] & 2018 & Shandong, China & 2014-2015 & $65.82 \pm 11.36$ & 60 & 20 & Good & $6(4-7)^{\mathrm{b}}$ \\
\hline
\end{tabular}

${ }^{\mathrm{a}}$ values are listed as Mean $\pm \mathrm{SD}$ (standard deviation), ${ }^{\mathrm{b}}$ values are listed as Median (IQ), ${ }^{\mathrm{c}}$ means not available, ${ }^{\mathrm{d}}$ values the Median (Range)

among these studies, and a random effects model was adopted (Fig. 5a). Subsequently, subgroup analysis was applied based on the location (China, Korea, Japan), and there was no heterogeneity in China $\left(\mathrm{I}^{2}=2.6 \%, P=0.425\right)$; However, articles from Korea had significant heterogeneity $\left(\mathrm{I}^{2}=\right.$ $79.2 \%, P=0.008$ ) (Fig. 5b).

\section{Sensitivity analysis and publication bias}

Clinical signs were pooled for positive rates on admission, and sensitivity analysis was performed, which indicated that the data changed little (Table S2). The case fatality rate in the sensitivity analysis forest plot was stable and had no significant effect on the merger rate (the combined rate was $18,95 \%$ CI: 0.16 to 0.21 ).

Egger's test and Begg's test were conducted to evaluate the publication bias, including 25 articles. The results showed that the Egger's test $\mathrm{t}$ value was $1.50(P=0.147)$, and the Begg's test $\mathrm{z}$ value was $1.14(P=0.252)$ (Fig. 6). Because the proportion of the fortieth reference datum was relatively high, when we removed it, the results showed the Egger's test $\mathrm{t}$ value was $1.22(P=0.235)$, and the Begg's test $\mathrm{z}$ value was $1.17(P=0.244)$.

\section{Discussion}

Our review identified a total of 4143 SFTS cases from 25 articles in SFTS- endemic regions including China, Korea and Japan. The main clinical and laboratory characteristics of SFTS were fever, gastrointestinal and neurological symptoms as well as thrombocytopenia and leukopenia. Fever was the most common symptom of SFTS patients, suggesting that it is an important indicator of the early stage of disease. The gastrointestinal and neurological symptoms included anorexia, nausea, vomiting, headache and other signs, but these symptoms were not very specific and were not associated with the progression of the disease; Further, some viral hemorrhagic fevers could cause these common symptoms, such as Rift Valley, Dengue fever and haemorrhagic fever with renal syndrome (HFRS) [47-49]. The clinical signs of fatal and non-fatal SFTS patients were 


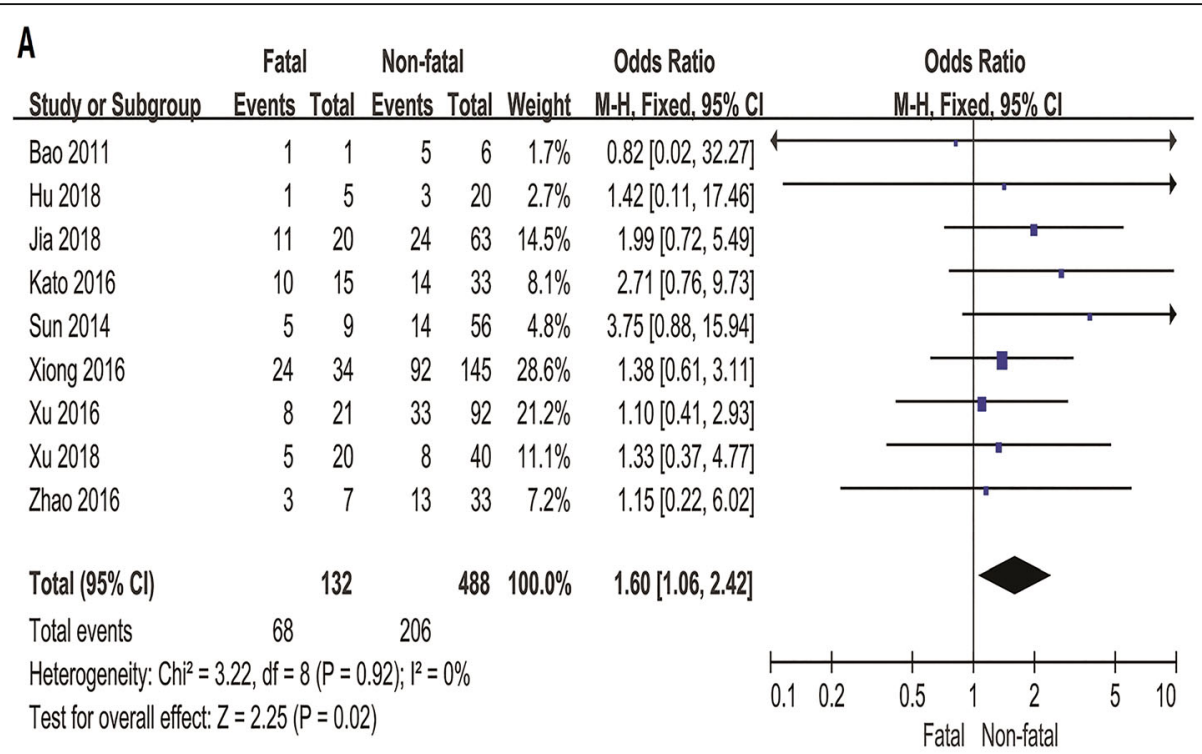

B

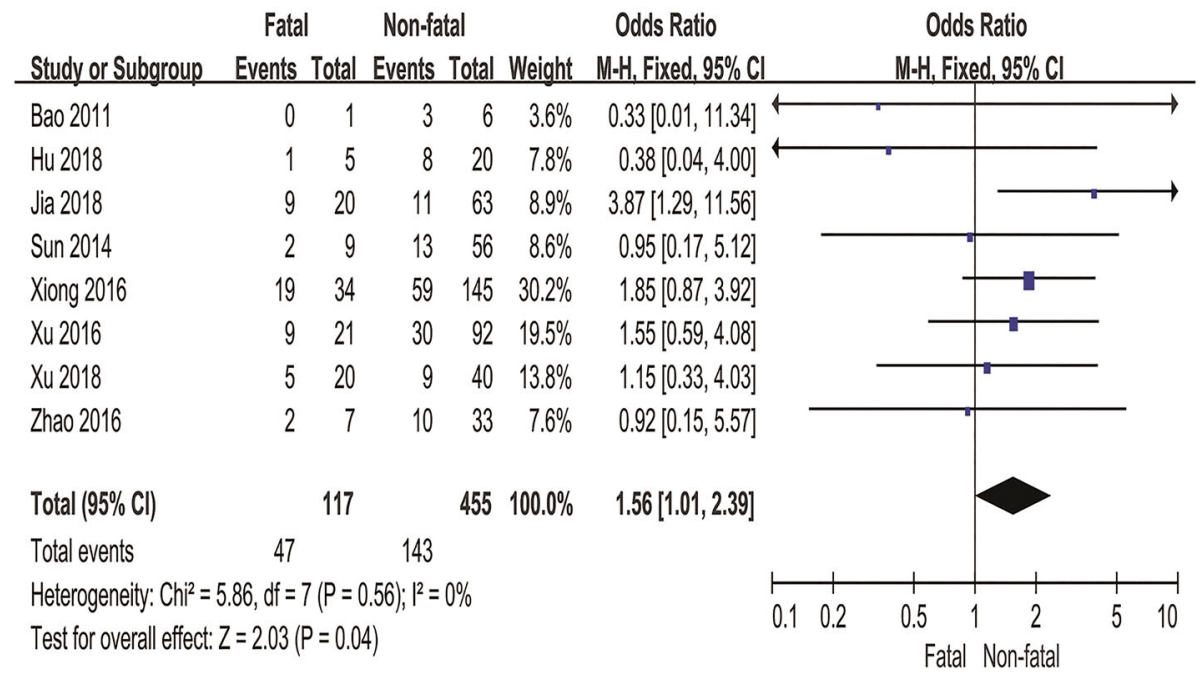

Fig. 2 Forest plots for the meta-analysis of a panel of the clinical signs and fatal outcomes of SFTS disease. a Diarrhea (on admission), $\mathbf{b}$ Vomiting (on admission)

studied, and the results showed that diarrhea and vomiting on admission were associated with fatal outcomes. Diarrhea and vomiting were obvious symptoms for patients, and most patients had these clinical symptoms. Clinicians could take appropriate treatment measures quickly on admission. The clinical signs, such as diarrhea and vomiting, had no differences during hospitalization. The reason might be that patients with clinical symptoms would be treated in time during hospitalization, while most of the patients had clinical symptoms before admission, so the treatment was delayed and the condition aggravated. In the intensive care unit (ICU) or ward, clinicians should pay special attention to patients with diarrhea and vomiting and timely treatment to prevent the disease from aggravating. We extracted the numbers of positive symptoms and total cases on admission to calculate the pooled positive rates of clinical symptoms. Meta-analysis showed that most clinical signs had significant heterogeneity, and the random effect model was used. Subgroup analysis explored the source of heterogeneity, and the results suggested that different provinces had impacts on heterogeneity. China has a vast territory and the incidence of SFTS was widespread. Although we issued diagnostic guidelines 


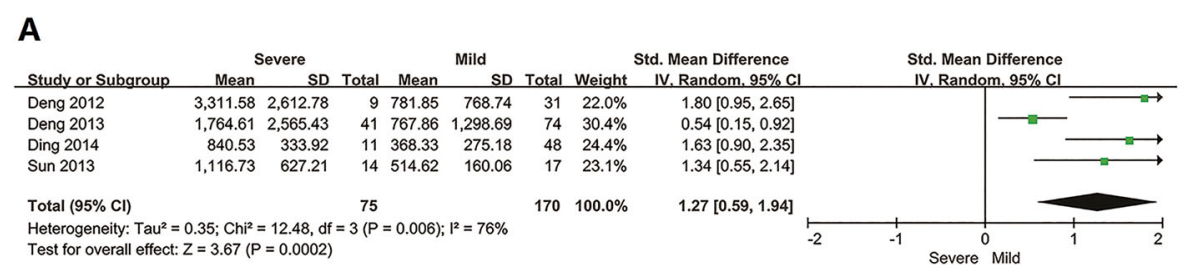

B

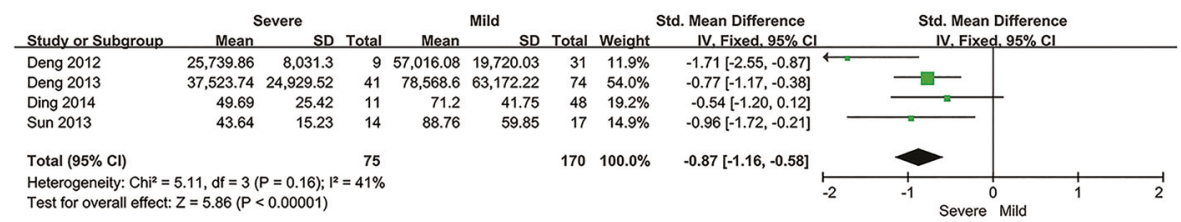

C

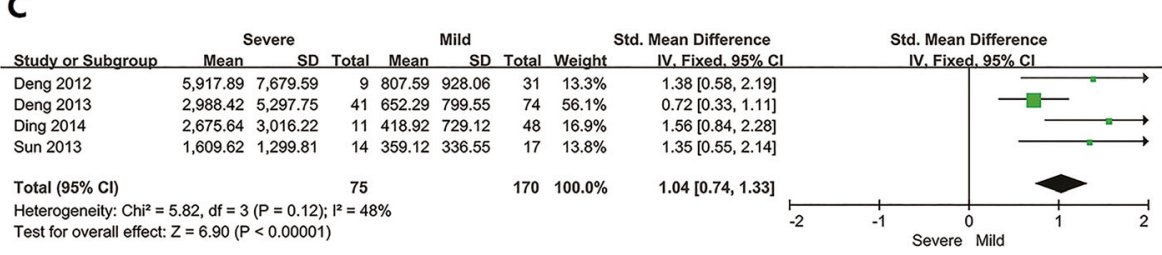

D

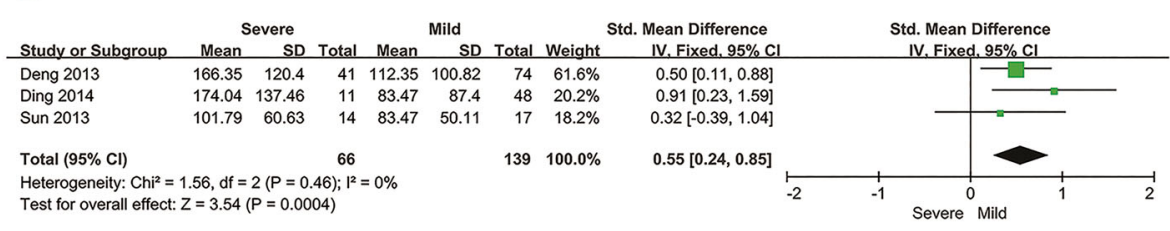

$\mathbf{E}$

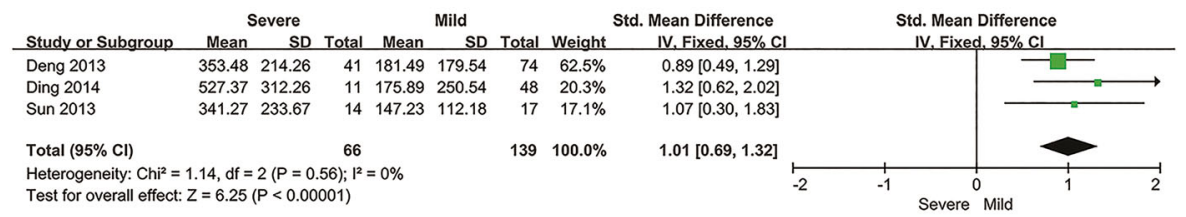

$\mathbf{F}$

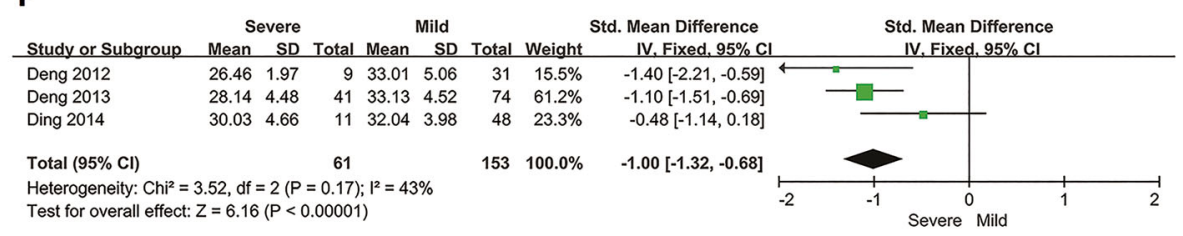

$\mathbf{G}$

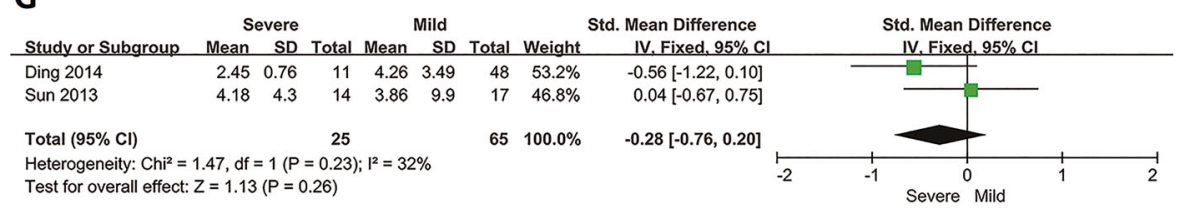

Fig. 3 Forest plots of meta-analysis on a panel of routine laboratory parameters. a $L D H, \mathbf{b}$ Platelet count, c CK, $\mathbf{d} A L T$, e AST, f Albumin, $\mathbf{g}$ WBC count

[50], there was a lack of diagnostic indicators and training work, suggesting that we must improve the unified criteria. According to the results, the pooled positive rates of clinical signs were observed to provide symptomatic diagnoses and treatment for SFTS patients.
The SFTS patients were classified into mild, severe or mild, common, severe and critical by clinical features and laboratory parameters in previous studies [26, 51]. In our study, routine laboratory parameters of mild and severe cases were analysed. Compared to patients with 
A

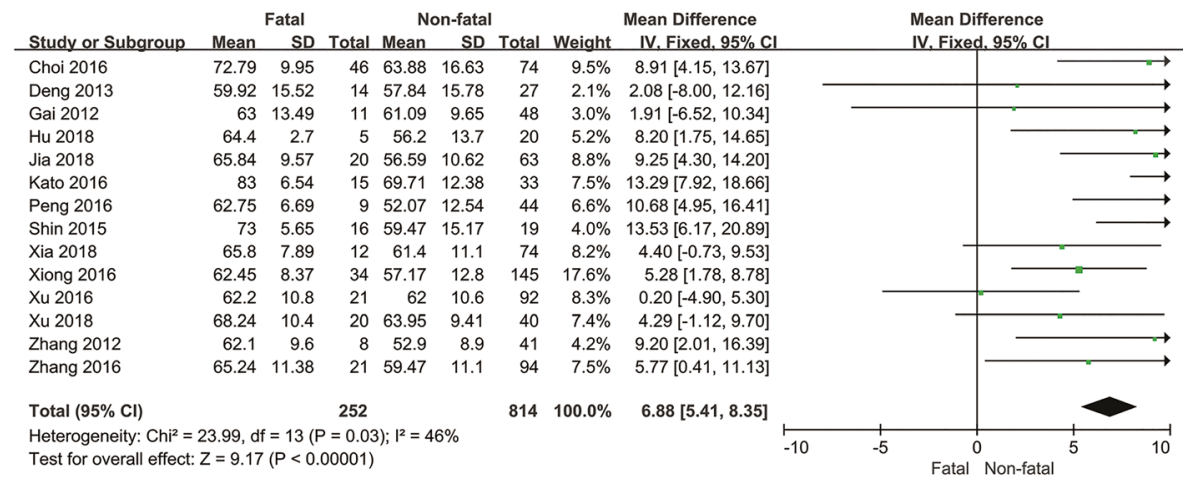

B

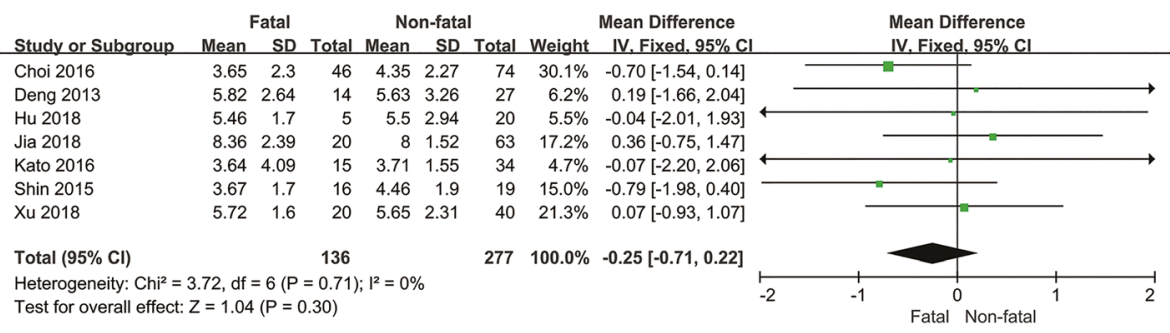

C

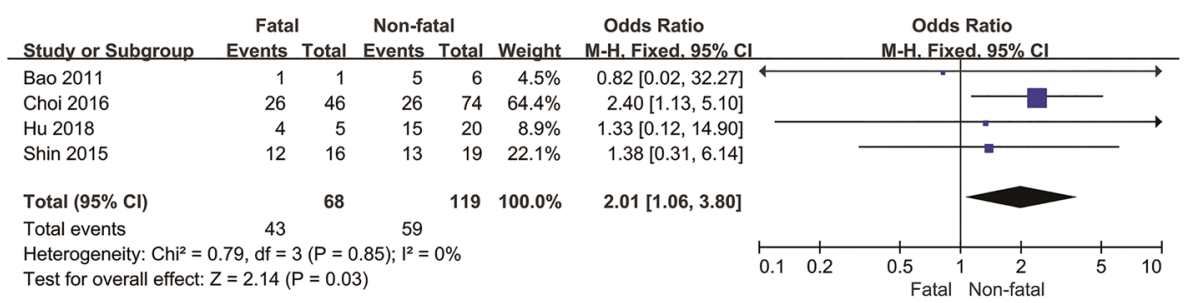

D

\begin{tabular}{|c|c|c|c|c|c|c|c|c|c|c|}
\hline Study or Subgroup & $\begin{array}{c}\text { Fatal } \\
\text { Events }\end{array}$ & & $\begin{array}{l}\text { Non-fa } \\
\text { Events }\end{array}$ & $\begin{array}{l}\text { Ital } \\
\text { Total }\end{array}$ & & $\begin{array}{l}\text { Odds Ratio } \\
\mathrm{M}-\mathrm{H}, \text { Random, } 95 \% \mathrm{Cl}\end{array}$ & & $\begin{array}{r}\text { Odd } \\
\text { M-H, Ran }\end{array}$ & $\begin{array}{l}\text { Is Ratio } \\
\text { dom, } 95 \% \mathrm{Cl}\end{array}$ & \\
\hline Choi 2016 & 11 & 46 & 15 & 74 & $22.0 \%$ & $1.24[0.51,2.99]$ & & & & \\
\hline Deng 2013 & 3 & 14 & 4 & 101 & $14.7 \%$ & $6.61[1.31,33.47]$ & & & & \\
\hline Kato 2016 & 2 & 15 & 19 & 33 & $14.5 \%$ & $0.11[0.02,0.58]$ & $t=$ & & & \\
\hline Shin 2015 & 2 & 16 & 2 & 19 & $11.2 \%$ & $1.21[0.15,9.76]$ & & & & \\
\hline Xu 2016 & 4 & 21 & 26 & 92 & $18.9 \%$ & $0.60[0.18,1.94]$ & & & & \\
\hline Xu 2018 & 6 & 20 & 10 & 40 & $18.7 \%$ & $1.29[0.39,4.25]$ & & & & \\
\hline Total $(95 \% \mathrm{Cl})$ & & 132 & & 359 & $100.0 \%$ & $0.98[0.40,2.42]$ & & & & \\
\hline Total events & 28 & & 76 & & & & & & & \\
\hline $\begin{array}{l}\text { Heterogeneity: } \mathrm{Tau}^{2}= \\
\text { Test for overall effect: }\end{array}$ & $\begin{array}{l}.76 ; \mathrm{Chi}^{2} \\
=0.04(\mathrm{P}\end{array}$ & $\begin{array}{l}=13.42 \\
=0.96\end{array}$ & 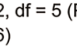 & $P=0.0$ & $02) ; I^{2}=63$ & & $0.1 \quad 0.2$ & ${ }^{0.5}$ Fata & $\begin{array}{lc}1 & 2 \\
1 & \text { Non-fatal }\end{array}$ & 10 \\
\hline
\end{tabular}

Fig. 4 Forest plots of meta-analysis on a panel of risk factors. a Age, $\mathbf{b}$ Interval between onset and admission, $\mathbf{c}$ Farming, $\mathbf{d}$ Tick bite

mild symptoms, the LDH, ALT, AST, and CK levels of patients with severe symptoms were elevated, but albumin and platelet levels were reduced. Leukocytopenia was an important characteristic for SFTS. Data for WBC counts were extracted and analysed, but the scarceness of the literature resulted in no differences between the patients with severe and mild symptoms. Because fever, fatigue, nausea, anorexia, and myalgia were the most frequent symptoms, they could represent the majority of patient conditions. Laboratory parameters and clinical symptoms could serve as references for disease classification and suspected patients.

The risk factors of SFTS patients were evaluated, including the risk factors of poor prognosis and the risk factor of contracting SFTS. Age was an important factor associated with SFTS disease and was a critical risk factor or determinant of morbidity and mortality in SFTS. Farmers accounted for the overwhelming majority of SFTS cases, and farming was a risk factors for SFTS. The transmission of SFTS occurs via tick bites, farmers 
A

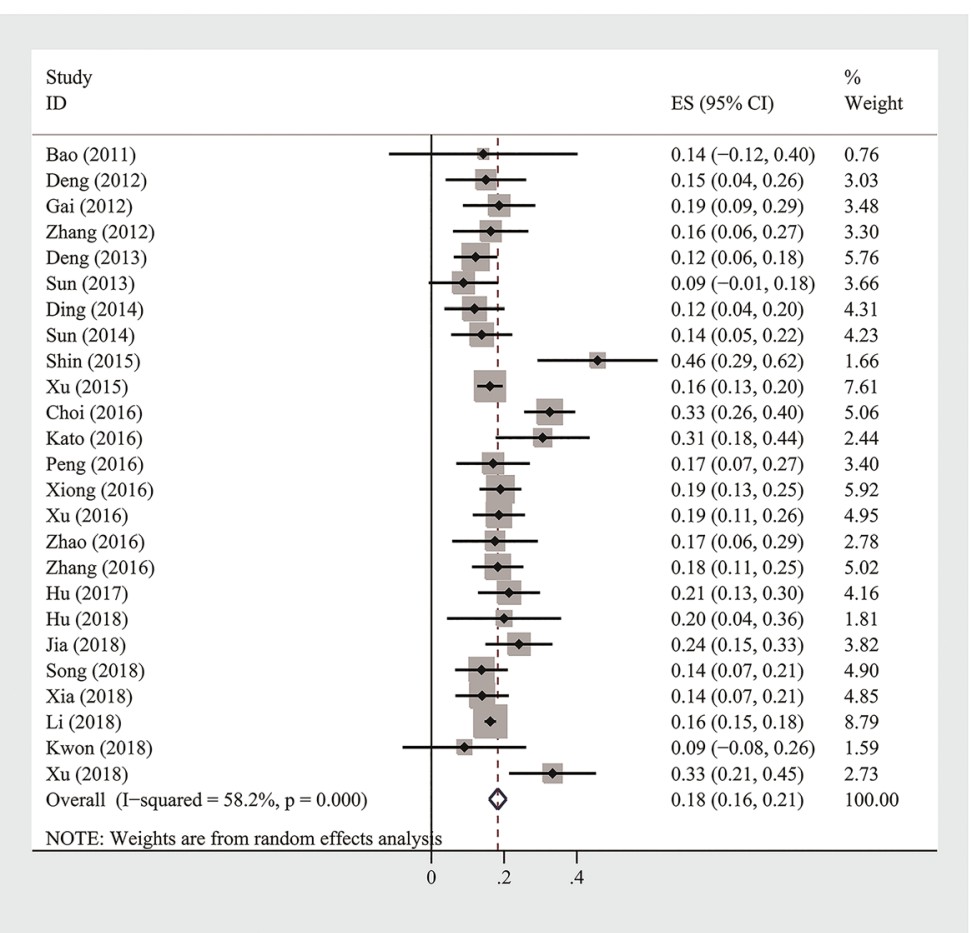

B

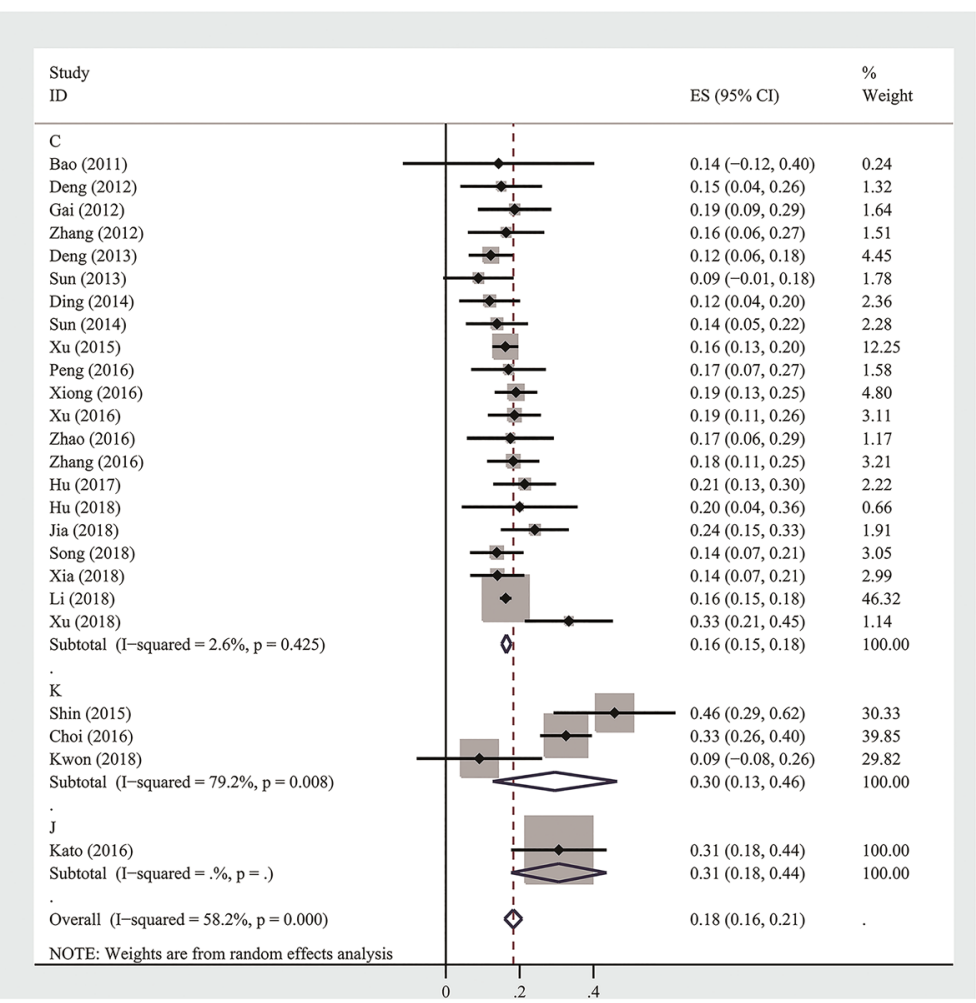

Fig. 5 a Forest plot of case fatality rate for SFTS patients, b Subgroup analysis forest plot according to location 
$\mathbf{A}$

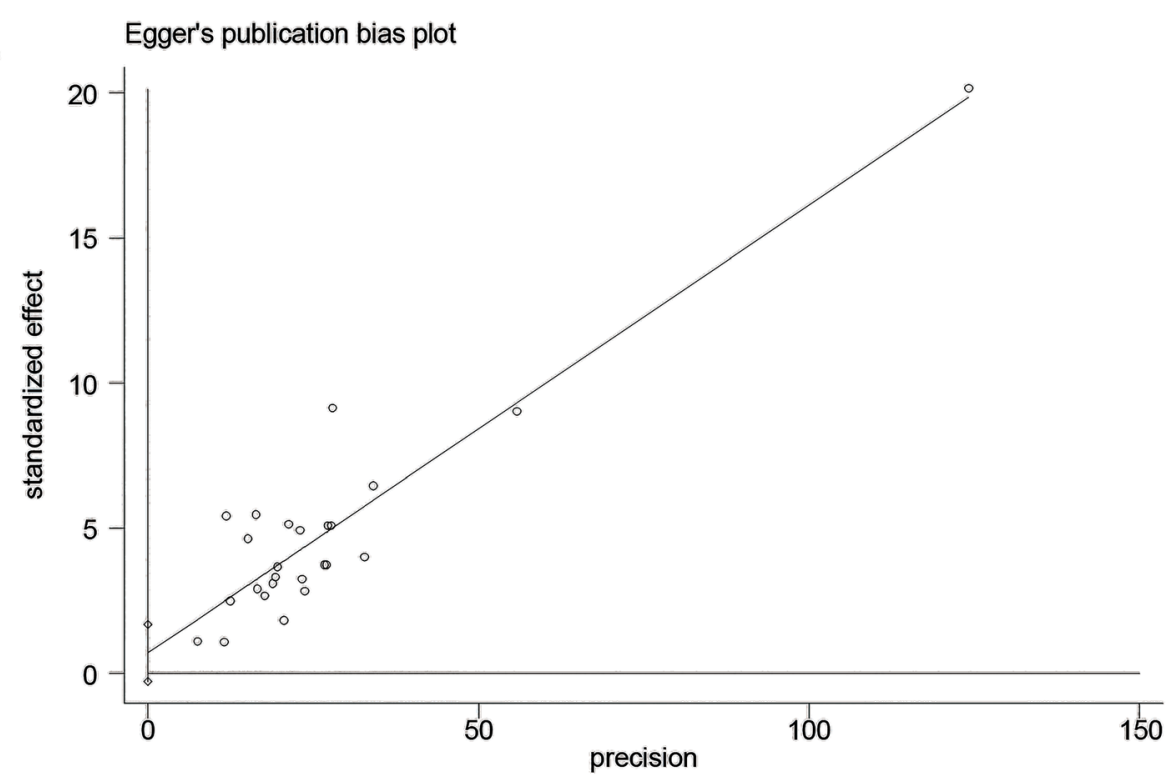

B

Begg's funnel plot with pseudo $95 \%$ confidence limits

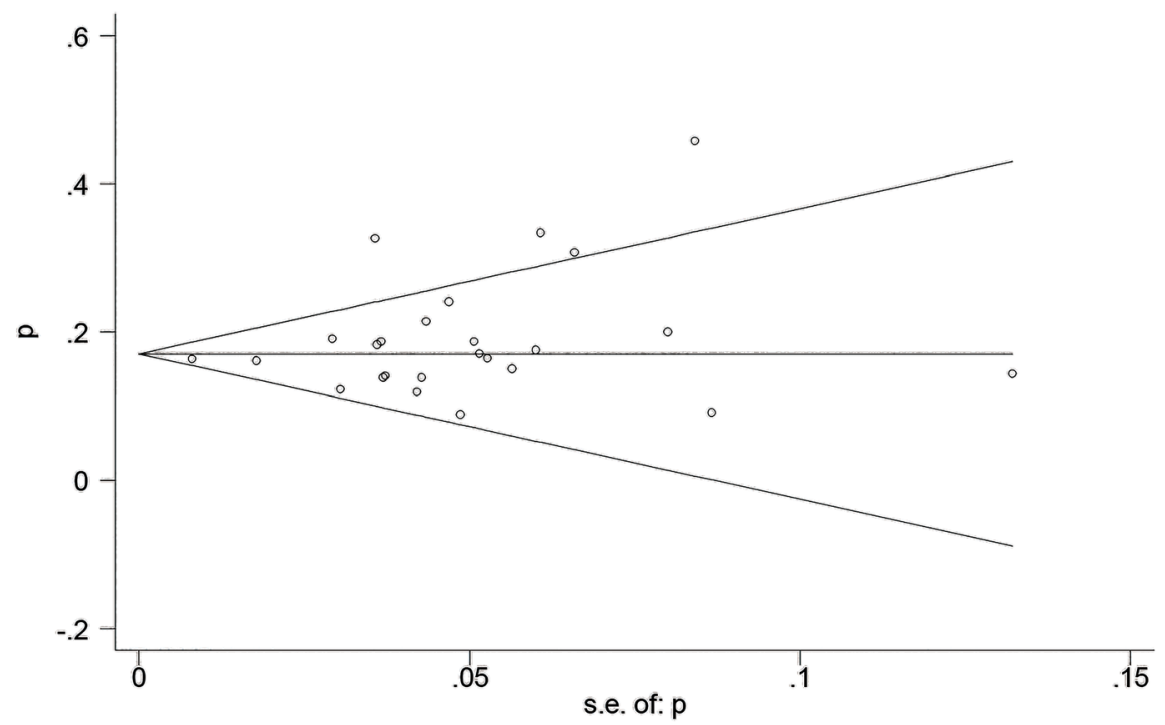

Fig. 6 Funnel plots for publication bias. a Egger's publication bias plot, b Begg's funnel plot

often work in fields; thus, it is possible that the probability of tick bites was greatly increased for farmers. Further analysis indicated that the occurrence of SFTS was related to tick bites but there was no association between tick bites and fatal outcomes. The reason for the strong heterogeneity might be that the distribution of ticks was different country to country. The six studies originated from 3 countries, including Japan (1 study), Korea (2 studies), and China (3 studies). Tick bites were a risk factor for the occurrence of SFTS, but the deaths of the patients were related to personal conditions and the severity of the disease.

The case-fatality rate of SFTS has varied widely among endemic areas. The case fatality rates in Japan and Korea were apparently higher than that in China $[14,15,33]$. The reasons for this discrepancy might include different 
notification systems and monitoring durations among the three countries, but the high case fatality from Japan or Korea, the most severe cases reported, just as China at an early stage of SFTS outbreak. We conducted subgroup analysis by region in the three countries. The significant heterogeneity derived from Korea. Because too little literature regarding Korea was included, we could not perform further analysis.

Compared to the previous articles, our meta-analysis had two different levels [52-54]. We summarized the distribution of clinical symptoms, and it was important to distinguish whether the clinical symptoms of each report occurred at the time of hospital visits, at the time of hospitalization or during hospitalization. Fatal and nonfatal patients on clinical symptoms and risk factors, and patients with severe and mild symptoms on routine laboratory parameters, were analysed; thus, we could draw more comprehensive conclusions.

This meta-analysis had some limitations. First, significant heterogeneity brought into question the suitability of performing this meta-analysis, however, the sensitivity analysis showed that the pooled rates were stable and no publication bias was found in our meta-analysis. Second, we could not analyse some indicators in these studies due to lacking data for clinical signs of patients with severe and mild symptoms. Third, the quality of the primary studies might have an impact on the results.

\section{Conclusions}

In conclusion, China was the country with the highest incidence of SFTS. May to July was peak of the epidemic, and farmers were a high-risk group. The risk factor of SFTS included age (poor prognosis) and tick bites (contracting SFTS). Patients with diarrhea and vomiting symptoms on admission should be noted to prevent the disease from aggravating. Clinicians could use the routine laboratory parameters (AST, ALT, LDH, CK, albumin, platelet count) and clinical symptoms (fever, fatigue, nausea, anorexia, myalgia) as references for clinically suspected cases, classification of SFTS and timely treatment, especially in basic hospitals. In addition, epidemiological (population distribution, regional distribution, and time distribution) and clinical characteristics should be combined and then developed public-health interventions for the control and prevention of SFTS.

\section{Supplementary information}

Supplementary information accompanies this paper at https://doi.org/10. 1186/s12879-020-05303-0.

Additional file 1: Table S1. The meta-analysis of clinical signs in two groups.

Additional file 2: Table S2. The main clinical symptoms of SFTS

patients on admission in this review.

\section{Abbreviations}

SFTS: Severe fever with thrombocytopenia syndrome; SFTSV: Severe fever with thrombocytopenia syndrome virus; HYSV: Huaiyangshan virus; NBV: New bunyavirus; SMD: Standard mean difference; MD: Mean difference;

SD: Standard deviation; OR: Odds ratio; Cl: Confidence intervals; LDH: Lactic acid dehydrogenase; ALT: Alanine aminotransferase; AST: Aspirate aminotransferase; CK: Creatine kinase; WBC: White blood cell

\section{Acknowledgements}

Not applicable.

\section{Authors' contributions}

$\mathrm{ZQH}$ and $\mathrm{BHW}$ designed the study, analysed the data and wrote the manuscript. $\mathrm{YL}$ and YHD collected the relevant papers and conducted the statistical analysis. HXM, $X L L$ and BLX analysed the data and offered suggestions. WSG and XYH reviewed the manuscript. The authors read and approved the final manuscript.

\section{Funding}

This work was sponsored by the Science and Technology Bureau of Henan Province $(152102310133,164100510008)$ and the National Natural Science Foundation of China (81573204)

Availability of data and materials

Not applicable.

Ethics approval and consent to participate

Not applicable.

\section{Consent for publication}

Not applicable.

\section{Competing interests}

The authors declare that they have no competing interests.

\section{Author details}

${ }^{1}$ College of Public Health, Zhengzhou University, Zhengzhou, China. ${ }^{2}$ Henan Province Center for Disease Control and Prevention, Zhengzhou, China.

${ }^{3}$ Henan Key Laboratory of Pathogenic Microorganisms, Zhengzhou, China.

Received: 5 September 2019 Accepted: 27 July 2020

Published online: 05 August 2020

References

1. Yu XJ, Liang MF, Zhang SY, Liu Y, Li JD, Sun YL, et al. Fever with thrombocytopenia associated with a novel bunyavirus in China. N Engl J Med. 2011;364(16):1523-32.

2. Zhang $Y Z$, Zhou DJ, Xiong $Y$, Chen $X P$, He YW, Sun Q, et al. Hemorrhagic fever caused by a novel tick-borne bunyavirus in Huaiyangshan, China. Chin J Epidemiol. 2011;32(3):209-20.

3. Xu BL, Liu LC, Huang XY, Ma H, Zhang Y, Du YH, et al. Metagenomic analysis of fever, thrombocytopenia and leukopenia syndrome (FTLS) in Henan Province, China: discovery of a new bunyavirus. PLoS Pathog. 2011; 7(11):e1002369.

4. Huang XY, Hu XN, Ma H, Du YH, Ma HX, Kang K, et al. Detection of new bunyavirus RNA by reverse transcription-loop-mediated isothermal amplification. J Clin Microbiol. 2014;52(2):531-5.

5. Zhu N, Tang WP, Cheng MJ, Shi XT. Advances in severe fever with thrombocytopenia syndrome (SFTS) and SFTS virus. China Trop Med. 2018; 18(3):282-8

6. Liu K, Zhou H, Sun RX, Yao HW, Wang LP, Mu D, et al. A national assessment of the epidemiology of severe fever with thrombocytopenia syndrome, China. Sci Rep. 2015;5:9679.

7. Takahashi T, Maeda K, Suzuki T, Ishido A, Shigeoka T, Tominaga T, et al. The first identification and retrospective study of severe fever with thrombocytopenia syndrome in Japan. J Infect Dis. 2014;209(6):816-27.

8. Kim KH, Yi J, Kim G, Choi SJ, Jun Kl, Kim NH, et al. Severe fever with thrombocytopenia syndrome, South Korea, 2012. Emerg Infect Dis. 2013; 19(11):1892-4

9. Luo LM, Zhao L, Wen HL, Zhang ZT, Liu JW, Fang LZ, et al. Haemaphysalis longicornis ticks as reservoir and vector of severe fever with 
thrombocytopenia syndrome virus in China. Emerg Infect Dis. 2015;21(10): 1770-6.

10. Zhuang $L$, Sun $Y$, Cui XM, Tang F, Hu JG, Wang LY, et al. Transmission of severe fever with thrombocytopenia syndrome virus by haemaphysalis longicornis ticks, China. Emerg Infect Dis. 2018;24(5):868-71.

11. Tang XY, Wu WL, Wang HF, Du YH, Liu LC, Kang K, et al. Human-to-human transmission of severe fever with thrombocytopenia syndrome bunyavirus through contact with infectious blood. J Infect Dis. 2013;207(5):736-9.

12. Jung IY, Choi W, Kim J, Wang E, Park SW, Lee WJ, et al. Nosocomial personto-person transmission of severe fever with thrombocytopenia syndrome. Clin Microbiol Infect. 2019;25(5):633.e1-4.

13. Zhan J, Wang Q, Cheng J, Hu B, Li J, Zhan F, et al. Current status of severe fever with thrombocytopenia syndrome in China. Virol Sin. 2017;32(1):51-62.

14. Korea Centers for Disease Control and Prevention. Infectious disease surveillance 2017, public health weekly report; 2017. https://is.cdc.go.kr/. Accessed 2 May 2019.

15. Saijo M. Severe fever with thrombocytopenia syndrome: epidemiology, pathophysiology, and development of specific treatement and prevention measures. Rinsho Ketsueki. 2018;59(10):2255-9.

16. Giang HTN, Banno K, Minh LHN, Trinh LT, Loc LT, Eltobgy A, et al. Dengue hemophagocytic syndrome: a systematic review and meta-analysis on epidemiology, clinical signs, outcomes, and risk factors. Rev Med Virol. 2018; 28(6):e2005.

17. Hozo SP, Djulbegovic B, Hozo I. Estimating the mean and variance from the median, range, and the size of a sample. BMC Med Res Methodol. 2005;5:13.

18. Wan X, Wang W, Liu J, Tong T. Estimating the sample mean and standard deviation from the sample size, median, range and/or interquartile range. BMC Med Res Methodol. 2014;14:135.

19. Luo $D$, Wan $X$, Liu J, Tong T. Optimally estimating the sample mean from the sample size, median, mid-range, and/or mid-quartile range. Stat Methods Med Res. 2018;27(6):1785-805.

20. Higgins JPT, Thompson SG, Deeks JJ, Altman DG. Measuring inconsistency in meta-analyses. BMJ. 2003;327(7414):557-60.

21. Stuck AE, Rubenstein LZ, Wieland D, Egger M, Davey SG, Schneider M, et al. Bias in meta-analysis detected by a simple, graphical test. BMJ. 1998; 316(7129):469.

22. Bao CJ, Wang H, Qi X, Hu JL, Zhou MH, Varma JK, et al. A family cluster of infections by a newly recognized bunyavirus in eastern China, 2007: further evidence of person-to-person transmission. Clin Infect Dis. 2011;53(12): 1208-14.

23. Deng $B$, Zhang $S$, Geng $Y$, Zhang $Y$, Wang $Y$, Yao W, et al. Cytokine and chemokine levels in patients with severe fever with thrombocytopenia syndrome virus. PLoS One. 2012;7(7):e41365.

24. Gai ZT, Zhang Y, Liang MF, Jin C, Zhang S, Zhu CB, et al. Clinical progress and risk factors for death in severe fever with thrombocytopenia syndrome patients. J Infect Dis. 2012;206(7):1095-102.

25. Zhang YZ, He YW, Dai YA, Xiong YW, Zheng H, Zhou DJ, et al. Hemorrhagic fever caused by a novel bunyavirus in China: pathogenesis and correlates of fatal outcome. Clin Infect Dis. 2012;54(4):527-33.

26. Deng BC, Zhou B, Zhang SJ, Zhu Y, Han LP, Geng YZ, et al. Clinical features and factors associated with severity and fatality among patients with severe fever with thrombocytopenia syndrome bunyavirus infection in Northeast China. PLoS One. 2013;8(11):e80802.

27. Sun L, Hu Y, Niyonsaba A, Tong Q, Lu L, Li H, et al. Detection and evaluation of immunofunction of patients with severe fever with thrombocytopenia syndrome. Clin Exp Med. 2014;14(4):389-95.

28. Ding YP, Liang MF, Ye JB, Liu QH, Xiong $\mathrm{CH}$, Long B, et al. Prognostic value of clinical and immunological markers in acute phase of SFTS virus infection. Clin Microbiol Infect. 2014;20(11):0870-8.

29. Sun J, Chai C, Lv H, Lin J, Wang C, Chen E, et al. Epidemiological characteristics of severe fever with thrombocytopenia syndrome in Zhejiang Province, China. Int J Infect Dis. 2014;25:180-5.

30. Xu Z, Cui N, Chen WW, Qin EQ, Nie WM, Yuan C, et al. Clinical characteristics in 422 patients with severe fever with thrombocytopenia syndrome. Infect Dis Info. 2015;28(1):28-32.

31. Shin J, Kwon D, Youn SK, Park JH. Characteristics and factors associated with death among patients hospitalized for severe fever with thrombocytopenia syndrome, South Korea, 2013. Emerg Infect Dis. 2015;21(10):1704-10.

32. Choi SJ, Park SW, Bae IG, Kim SH, Ryu SY, Kim HA, et al. Severe fever with thrombocytopenia syndrome in South Korea, 2013-2015. PLoS Negl Trop Dis. 2016;10(12):e0005264.
33. Kato H, Yamagishi T, Shimada T, Matsui T, Shimojima M, Saijo M, et al. Epidemiological and clinical features of severe fever with thrombocytopenia syndrome in Japan, 2013-2014. PLoS One. 2016;11(10):e0165207.

34. Peng C, Wang H, Zhang W, Zheng X, Tong Q, Jie S, et al. Decreased monocyte subsets and TLR4 mediated functions in patients with acute severe fever with thrombocytopenia syndrome (SFTS). Int J Infect Dis. 2016;43:37-42.

35. Xiong $S$, Zhang $W$, Li M, Xiong $Y$, Li M, Wang $H$, et al. A simple and practical score model for predicting the mortality of severe fever with thrombocytopenia syndrome patients. Medicine. 2016;95(52):e5708.

36. Xu HR, Zhao H. Analysis on surveillance data of severe fever with thrombocytopenia syndrome in Jinan City in 2011-2015. Modern Prev Med. 2016;43(18):3419-22.

37. Zhao HY, Sun J, Yan XM, Xiong YL, Huang R, Zhang YY, et al. Clinical characteristics and risk factors for mortality of patients with severe fever with thrombocytopenia syndrome. Chin J Infect Dis. 2016;34(1):15-8.

38. Zhang W, Li M, Xiong S, Wang H, Xiong Y, Li M, et al. Decreased myeloid dendritic cells indicate a poor prognosis of severe fever with thrombocytopenia syndrome patients. Int J Infect Dis. 2017;54:113-20.

39. Hu J, Li Z, Hong L, Bao C, Zhang Z, Zhang H, et al. Preliminary fast diagnosis of severe fever with thrombocytopenia syndrome with clinical and epidemiological parameters. PLoS One. 2017;12(7):e0180256.

40. Hu J, Li S, Zhang X, Zhao H, Yang M, Xu L, et al. Correlations between clinical features and death in patients with severe fever with thrombocytopenia syndrome. Medicine. 2018;97(22):e10848.

41. Jia B, Wu W, Huang R, Wang G, Song P, Li Y, et al. Characterization of clinical features and outcome for human-to-human transmitted severe fever with thrombocytopenia syndrome. Infect Dis. 2018;50(8):1-8.

42. Song YH, Sun ML, Wen KY. Epidemiological analysis on cases of severe fever with thrombocytopenia syndrome in Chaohu City, 2011-2017. Anhui J Prev Med. 2018;24(3):184-7.

43. Xia GM, Zou GZ, Ye J, Gao YF, Li F, Jin L. Clinical characteristics and prognostic factors of fever with thrombocytopenia syndrome in Anhui Province. Anhui J Med. 2018:39(7):854-7.

44. Li H, Lu QB, Xing B, Zhang S, Liu K, Du J, et al. Epidemiological and clinical features of laboratory-diagnosed severe fever with thrombocytopenia syndrome in China, 2011-17: a prospective observational study. Lancet Infect Dis. 2018;18(10):1127-37.

45. Kwon JS, Kim MC, Kim JY, Jeon NY, Ryu BH, Hong J, et al. Kinetics of viral load and cytokines in severe fever with thrombocytopenia syndrome. J Clin Virol. 2018;101:57-62.

46. Xu X, Sun Z, Liu J, Zhang J, Liu T, Mu X, et al. Analysis of clinical features and early warning indicators of death from severe fever with thrombocytopenia syndrome. Int J Infect Dis. 2018;73:43-8.

47. Kahlon SS, Peters CJ, Leduc J, Muchiri EM, Muchiri S, Njenga MK, et al. Severe rift valley fever may present with a characteristic clinical syndrome. Am J Trop Med Hyg. 2010;82(3):371-5.

48. Deshwal R, Qureshi MI, Singh R. Clinical and laboratory profile of dengue fever. J Assoc Physicians India. 2015;63(12):30-2.

49. Ma T, Xie GX, Xu Q, Hong L, Zhang Z, Feng LJ, et al. Epidemiological characteristics of hemorrhagic fever with renal syndrome, Nanjing, 20112016. Modern Prev Med. 2017;44(23):4231-7.

50. Ministry of Health of People's Republic of China. National guideline for prevention and control of severe fever with thrombocytopenia syndrome (2010 edition). Chin J Clin Infect Dis. 2011;4(4):193-4 http://www. wanfangdata.com.cn/details/detail.do?_type=perio\&id=zhlcgrbzz201104001. Accessed 2 May 2019

51. Yuan YM, Cui N, Yuan C. Recommendations for nomenclature, clinical staging and typing of severe fever with thrombocytopenia syndrome. Chin $J$ Infect Dis. 2016;34(1):57-8.

52. Liu S, Chai C, Wang C, Amer S, Lv HK, He HX, et al. Systematic review of severe fever with thrombocytopenia syndrome: virology, epidemiology, and clinical characteristics. Rev Med Virol. 2014;24(2):90-102.

53. Chen Y, Jia B, Liu Y, Huang R, Chen JH, Wu C, et al. Risk factors associated with fatality of severe fever with thrombocytopenia syndrome: a metaanalysis. Oncotarget. 2017;8(51):89119-29.

54. Liu MM, Lei XY, Yu XJ. Meta-analysis of the clinical and laboratory parameters of SFTS patients in China. Virol J. 2016;13(1):198.

\section{Publisher's Note}

Springer Nature remains neutral with regard to jurisdictional claims in published maps and institutional affiliations. 